\title{
Indomethacin for intracranial hypertension secondary to severe traumatic brain injury in adults (Review)
}

Martín-Saborido C, López-Alcalde J, Ciapponi A, Sánchez Martín CE, Garcia Garcia E, Escobar Aguilar G, Palermo MC, Baccaro FG

Martín-Saborido C, López-Alcalde J, Ciapponi A, Sánchez Martín CE, Garcia Garcia E, Escobar Aguilar G, Palermo MC, Baccaro FG. Indomethacin for intracranial hypertension secondary to severe traumatic brain injury in adults.

Cochrane Database of Systematic Reviews 2019, Issue 11. Art. No.: CD011725.

DOI: 10.1002/14651858.CD011725.pub2.

www.cochranelibrary.com 
TABLE OF CONTENTS

HEADER 1

ABSTRACT

PLAIN LANGUAGE SUMMARY

SUMMARY OF FINDINGS

BACKGROUND

OBJECTIVES

METHODS

RESULTS

Figure 1.

DISCUSSION

AUTHORS' CONCLUSIONS

ACKNOWLEDGEMENTS

REFERENCES

CHARACTERISTICS OF STUDIES

APPENDICES

CONTRIBUTIONS OF AUTHORS

DECLARATIONS OF INTEREST

SOURCES OF SUPPORT

DIFFERENCES BETWEEN PROTOCOL AND REVIEW

1

2

3

5

6

6

8

9

10

10

10

12

15

16

21

23

23 
[Intervention Review]

\section{Indomethacin for intracranial hypertension secondary to severe traumatic brain injury in adults}

Carlos Martín-Saborido1a, Jesús López-Alcalde2,3,4b, Agustín Ciapponi ${ }^{5}$, Carlos Enrique Sánchez Martín 6 , Elena Garcia Garcia7, Gema Escobar Aguilar 8 , Maria Carolina Palermo9 ${ }^{9}$, Fernando G Baccaro ${ }^{10}$

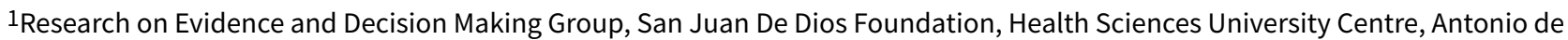
Nebrija University, Madrid, Spain. ${ }^{2}$ Cochrane Associate Centre of Madrid, Madrid, Spain. ${ }^{3}$ Faculty of Medicine, Universidad Francisco de Vitoria, Pozuelo de Alarcón, Spain. ${ }^{4}$ Clinical Biostatistics Unit, Instituto Ramón y Cajal de Investigación Sanitaria, Madrid, Spain. ${ }^{5}$ Argentine Cochrane Centre, Institute for Clinical Effectiveness and Health Policy (IECS-CONICET), Buenos Aires, Argentina. ${ }^{6}$ Department of Anesthesiology, San Carlos Clinical Hospital, Madrid, Spain. ${ }^{7}$ Health Services Research Department, San Juan De Dios Foundation, Madrid, Spain. 8Health Services Research Unit, San Juan de Dios Foundation/San Rafael-Nebrija Health Sciences Center, Nebrija University, Madrid, Spain. 9Institute for Clinical Effectiveness and Health Policy (IECS-CONICET), University of Buenos Aires, Buenos Aires, Argentina. ${ }^{10}$ Intensive Care Unit, Juan A Fernández Hospital, Buenos Aires, Argentina

${ }^{a}$ The authors contributed equally to this work.. ${ }^{b}$ The authors contributed equally to this work.

Contact address: Carlos Martín-Saborido, Research on Evidence and Decision Making Group, San Juan De Dios Foundation, Health Sciences University Centre, Antonio de Nebrija University, Paseo de la Habana 70 bis, Madrid, Comunidad de Madrid, 28036, Spain. c.m.saborido@gmail.com.

Editorial group: Cochrane Injuries Group.

Publication status and date: New, published in Issue 11, 2019.

Citation: Martín-Saborido C, López-Alcalde J, Ciapponi A, Sánchez Martín CE, Garcia Garcia E, Escobar Aguilar G, Palermo MC, Baccaro FG. Indomethacin for intracranial hypertension secondary to severe traumatic brain injury in adults. Cochrane Database of Systematic Reviews 2019, Issue 11. Art. No.: CD011725. DOI: 10.1002/14651858.CD011725.pub2.

Copyright @ 2019 The Cochrane Collaboration. Published by John Wiley \& Sons, Ltd.

\section{A B S T R A C T}

\section{Background}

Among people who have suffered a traumatic brain injury, increased intracranial pressure continues to be a major cause of early death; it is estimated that about 11 people per 100 with traumatic brain injury die.

Indomethacin (also known as indometacin) is a powerful cerebral vasoconstrictor that can reduce intracranial pressure and, ultimately, restore cerebral perfusion and oxygenation. Thus, indomethacin may improve the recovery of a person with traumatic brain injury.

\section{Objectives}

To assess the effects of indomethacin for adults with severe traumatic brain injury.

\section{Search methods}

We ran the searches from inception to 23 August 2019. We searched the Cochrane Central Register of Controlled Trials (CENTRAL; 2019, Issue 8) in the Cochrane Library, Ovid MEDLINE, Ovid Embase, CINAHL Plus (EBSCO), four other databases, and clinical trials registries. We also screened reference lists and conference abstracts, and contacted experts in the field.

\section{Selection criteria}

Our search criteria included randomised controlled trials (RCTs) that compared indomethacin with any control in adults presenting with severe traumatic brain injury associated with elevated intracranial pressure, with no previous decompressive surgery. 


\section{Data collection and analysis}

Two review authors independently decided on the selection of the studies. We followed standard Cochrane methods.

\section{Main results}

We identified no eligible studies for this review, either completed or ongoing.

\section{Authors' conclusions}

We found no studies, either completed or ongoing, that assessed the effects of indomethacin in controlling intracranial hypertension secondary to severe traumatic brain injury. Thus, we cannot draw any conclusions about the effects of indomethacin on intracranial pressure, mortality rates, quality of life, disability or adverse effects.

This absence of evidence should not be interpreted as evidence of no effect for indomethacin in controlling intracranial hypertension secondary to severe traumatic brain injury. It means that we have not identified eligible research for this review.

\section{PLAIN LANGUAGE SUMMARY}

\section{Indomethacin for controlling internal skull pressure in adults with severe traumatic brain injury}

\section{Review question}

Indomethacin (also known as indometacin) is a drug that causes vasoconstriction, that is, it makes blood vessels narrower. We were interested in finding out how treating adults (18 years and over) with indomethacin, compared with not administering indomethacin, affects raised pressure inside the skull (cranium) that has been caused by a severe traumatic brain injury.

\section{Background}

Traumatic brain injury occurs when an external force injures the head. The trauma damages the brain in two different phases; firstly, at the time of impact, and then during the minutes and days following the injury, when the pressure within the skull rises (raised intracranial pressure). This is important because raised intracranial pressure is a common cause of death and disability in people with a brain injury. It is estimated that about $11 \%$ of people with traumatic brain injury die.

Indomethacin is a drug that some researchers think can reduce intracranial pressure, and so improve the recovery of people with traumatic brain injury.

\section{Search date}

We searched for randomised controlled studies, which provide the most reliable evidence, up to 23 August 2019.

\section{Study characteristics}

We found that no randomised studies, either completed or ongoing, had investigated our review question.

\section{Key results}

We found no trials, either completed or ongoing, that answered our review question. Thus, this review cannot draw any conclusions about the effects of indomethacin on raised intracranial pressure, mortality rates, quality of life, disability or adverse effects in adults.

\section{Quality of the evidence}

There is no evidence from randomised studies to guide healthcare professionals about the effects (benefits or harms) of using indomethacin to control the raised intracranial pressure that follows severe traumatic brain injury in adults. Therefore, it was not possible to assess the quality of the evidence.

\section{Conclusions}

We are uncertain about the effects of indomethacin in adults with severe traumatic brain injury. This absence of evidence should not be interpreted as evidence that indomethacin does not work, but means that we did not identify eligible research for this review, and that the effects of indomethacin have yet to be determined by appropriately designed clinical studies. 


\section{SUMMARY OF FINDINGS}

Summary of findings for the main comparison. Indomethacin for controlling intracranial hypertension secondary to severe traumatic brain injury

Indomethacin for controlling intracranial hypertension secondary to severe traumatic brain injury

Patient or population: adults presenting with elevated intracranial pressure secondary to a traumatic brain injury

Setting: emergency department

Intervention: indomethacin

Comparison: not using indomethacin

\begin{tabular}{|c|c|c|c|c|c|c|}
\hline \multirow[t]{2}{*}{ Outcomes } & \multicolumn{2}{|c|}{$\begin{array}{l}\text { Anticipated absolute effects* } \\
(95 \% \mathrm{Cl})\end{array}$} & \multirow[t]{2}{*}{$\begin{array}{l}\text { RR } \\
(95 \% \mathrm{CI})\end{array}$} & \multirow{2}{*}{$\begin{array}{l}\text { No of partici- } \\
\text { pants } \\
\text { (studies) }\end{array}$} & \multirow{2}{*}{$\begin{array}{l}\text { Certainty of } \\
\text { the evidence } \\
\text { (GRADE) }\end{array}$} & \multirow[t]{2}{*}{ Comments } \\
\hline & $\begin{array}{l}\text { Risk with } \\
\text { control }\end{array}$ & $\begin{array}{l}\text { Risk with in- } \\
\text { domethacin }\end{array}$ & & & & \\
\hline Intracranial pressure (mmHg) & See comment & & - & (0 RCTs) & - & $\begin{array}{l}\text { No trials met the inclusion } \\
\text { criteria, so there are no data } \\
\text { for this outcome. }\end{array}$ \\
\hline Mortality one month after the start of therapy & See comment & & - & (0 RCTs) & - & $\begin{array}{l}\text { No trials met the inclusion } \\
\text { criteria, so there are no data } \\
\text { for this outcome. }\end{array}$ \\
\hline $\begin{array}{l}\text { Adverse effects considered as serious by either the } \\
\text { patient or the clinician }\end{array}$ & See comment & & - & (0 RCTs) & - & $\begin{array}{l}\text { No trials met the inclusion } \\
\text { criteria, so there are no data } \\
\text { for this outcome. }\end{array}$ \\
\hline $\begin{array}{l}\text { Disability (measured by the Glasgow Outcome Scale; } \\
\text { higher score is better) }\end{array}$ & See comment & & - & (0 RCTs) & - & $\begin{array}{l}\text { No trials met the inclusion } \\
\text { criteria, so there are no data } \\
\text { for this outcome. }\end{array}$ \\
\hline $\begin{array}{l}\text { Differences in quality of life (measured with a vali- } \\
\text { dated scale) }\end{array}$ & See comment & & - & (0 RCTs) & - & $\begin{array}{l}\text { No trials met the inclusion } \\
\text { criteria, so there are no data } \\
\text { for this outcome. }\end{array}$ \\
\hline
\end{tabular}

*The risk in the intervention group (and its $95 \%$ confidence interval) is based on the assumed risk in the comparison group and the relative effect of the intervention (and its $95 \% \mathrm{Cl}$ ).

Cl: confidence interval; $\mathbf{R C T}$ : randomised controlled trial 
gh quality: further research is very unlikely to change our confidence in the estimate of effect.

Moderate quality: further research is likely to have an important impact on our confidence in the estimate of effect and may change the estimate.

Low quality: further research is very likely to have an important impact on our confidence in the estimate of effect and is likely to change the estimate.

Very low quality: we are very uncertain about the estimate. 


\section{B A C K G R O U N D}

\section{Description of the condition}

Traumatic brain injury (TBI), also known as intracranial injury, occurs when an external force injures the brain. TBI can be classified on the basis of severity, mechanism (closed or penetrating head injury), and other features (e.g. occurring in a specific location or over a widespread area) (Chelly 2017). Brain trauma can be caused by a direct impact (e.g. falls, motor vehicle crashes, violence) or by acceleration (e.g. shaking a baby). Most of these injuries are preventable (Davanzo 2017), and prevention measures do exist. These include the use of technology - such as seat belts and sportsor motorcycle helmets - to protect a person during a crash, as well as efforts to reduce the number of motor vehicle crashes through safety education programmes and enforcement of traffic laws (Reilly 2007).

The damage that occurs at the time of impact is called the primary injury. In addition, brain trauma causes secondary injury, which is the damage that evolves over time following the trauma. Secondary brain injury is due to a variety of events that take place in the minutes and days following the injury. These processes, which include alterations in cerebral blood flow and pressure within the skull, contribute substantially to the damage caused by the primary injury. A person's chance of recovery from head injury depends on both the primary impact and the secondary injury mechanisms. TBI can cause a variety of physical, cognitive, social, emotional, and behavioural effects. Some people can survive an injury and experience complete recovery, while others may become permanently disabled (Littlejohns 2005).

TBI is a frequent cause of mortality and morbidity, especially in young adults. In western countries, injuries are the leading cause of death in people under the age of 45 years (CDC 2015). Every year, about 1.5 million people die in the period after the injury from causes related to their original TBI, and at least 10 million people are hospitalised as a direct result of TBI (CDC 2015). In other studies, the annual incidence rate for hospital-treated severe TBI injury is between 7 and 20 people per 100,000 , with an average mortality rate of about 15 per 100,000 and a case fatality rate of about 11 per 100 (Andelic 2012).

Among survivors of head injury, many people experience permanent disability (CDC 2015). The direct costs (e.g. medical expenses) and indirect costs (e.g. lost wages) of TBI in the USA have been estimated to be up to USD 76.5 billion per year, according to the Centers for Disease Control and Prevention (Bergen 2008; CDC 2015; Ponsford 2013).

\section{Description of the intervention}

Special interventions are required to minimise factors contributing to secondary brain trauma and brain oedema (the abnormal accumulation of water within the brain) (Donkin 2010). These interventions include head elevation, sedation, cerebrospinal fluid drainage, osmotic therapy (administration of hypertonic saline to shrink cerebral tissue), barbiturates, hyperventilation, hypothermia and indomethacin (also known as indometacin) infusion (Meyer 2010). Indomethacin is a non-steroidal antiinflammatory agent with anti-inflammatory, analgesic and antipyretic activity. Its pharmacological effect is mediated through inhibition of the enzyme cyclo-oxygenase, which promotes vasoconstriction.

\section{How the intervention might work}

Refractory increases in intracranial pressure (ICP) continue to be one of the most important causes of early death in people with brain injury (Alarcon 2017). As the primary cerebral injury is irreversible, the prevention of secondary injury resulting from ICP and the promotion of adequate cerebral blood flow are important endpoints to achieve in people with TBI (NICE 2014; Sullivan 2000).

Post-traumatic brain oedema is common and contributes to raised ICP. Due to the limited space for volume expansion, and the need to maintain ICP at its normal level ( $8 \mathrm{mmHg}$ to $13 \mathrm{mmHg}$ ), the volume of the brain is more effectively controlled than that of other organs. The control of brain volume is based on the intact blood-brain barrier, so a disturbance of capillary permeability for small solutes is one essential triggering mechanism behind the development of brain oedema, according to the Lund Concept (Muzevic 2013). This concept was introduced in 1990 to 1991 at the University Hospital of Lund, in Sweden. It is a theoretical approach for the treatment of severe head injury mainly based on the physiological and pathophysiological haemodynamic principles of brain volume and regulation of brain perfusion, and is characterised by the treatment of ICP and maintenance of cerebral perfusion (Grände 2006). For this reason, vasoconstriction and negative fluid balances have been used to attempt to reduce ICP in people with TBI.

Indomethacin is a potent cerebral arteriolar vasoconstrictor that could interrupt the vicious cycle that occurs during long ICP periods (i.e. ICP above $25 \mathrm{mmHg}$ for more than seven days) (Bratton 2007), extinguishing these waves and, ultimately, restoring cerebral perfusion and oxygenation (Imberti 2005). The mechanisms whereby indomethacin reduces ICP are not fully understood, but are thought to include a decrease in production of cerebral vasodilating prostaglandins, through cyclooxygenase inhibition or regulation. Indomethacin is a nonselective cyclo-oxygenase- 1 and cyclo-oxygenase- 2 inhibitor, and it has not yet been determined whether indomethacin primarily inhibits cyclo-oxygenase-1 or cyclo-oxygenase-2. The cerebral haemodynamic effects of indomethacin are not shared by other cyclo-oxygenase inhibitors, such as ibuprofen, diclofenac, naproxen, or sodium salicylate (Pun 2017). This suggests an alternative contribution to indomethacin-induced cerebral vasoconstriction, other than inhibition of cyclo-oxygenase and blockade of prostacyclin receptors acting directly to produce vasoconstriction of cerebral blood vessels and reduce brain swelling (Godoy 2017). Alternatively, indomethacin may have a direct neuroprotective effect that is shown after non-selective cyclo-oxygenase inhibition (Girgis 2013). These effects may be due to a non-prostaglandin-mediated mechanism that interferes directly with the regulation of cerebrovascular tone, mediated by extracellular pH (Girgis 2013).

Since indomethacin acts as a cerebral precapillary vasoconstrictor, it has also been studied in people with head injuries. Different studies demonstrated that indomethacin can decrease ICP and improve cerebral perfusion pressure (CPP) in people with refractory ICP who demonstrate no response to other or classic therapies (Godoy 2012; Rasmussen 2004). 
The use of indomethacin in treating raised ICP secondary to $\mathrm{TBI}$ is controversial. Clinical studies suggest that it may be useful in the management of intracranial hypertension, when used in combination with standard techniques, by decreasing cerebral blood flow and reducing ICP during the restoration of the blood-brain barrier (Smirl 2014). Data from animal models and randomised controlled studies with preterm infants have shown that intravenous indomethacin produces rapid, significant reductions in cerebral blood flow (El-Mashad 2017). Controlled studies in healthy volunteers showed a reduction in cerebral blood flow (NCT01280006). Case series involving people with severe TBI suggest that indomethacin boluses of $30 \mathrm{mg}$ to $50 \mathrm{mg}$ reduce ICP by $37 \%$ to $52 \%$, reduce cerebral blood flow by $26 \%$, and cause a modest $14 \%$ increase in CPP (Godoy 2017). There are questions about possible cerebral ischaemia, since indomethacin causes vasoconstriction. However, there is no evidence that indomethacin causes ischaemic damage from examination using diffusionweighted magnetic resonance imaging (MRI) (Biestro 1995; Godoy 2005).

Indomethacin can produce side effects in a minority of patients (less than 10\%). In those affected, transient renal insufficiency, jaundice, elevated liver function test values and headache occur more frequently than dizziness, dyspepsia, nausea and other upper gastrointestinal symptoms. Very infrequently it can cause acute respiratory distress and congestive heart failure (Medscape monograph 2019), which can be fatal.

\section{Why it is important to do this review}

To date, experimental and clinical studies suggest a beneficial effect from the use of indomethacin in adults with uncontrolled ICP, but its use is still controversial. A systematic review will clarify the evidence in relation to this important issue.

\section{O B JECTIVES}

To assess the effects of indomethacin for people with severe traumatic brain injury.

\section{METHODS}

\section{Criteria for considering studies for this review}

\section{Types of studies}

Randomised controlled trials (RCTs).

\section{Types of participants}

We included adults ( $\geq 18$ years old) presenting with severe traumatic brain injury (defined as having an initial Glasgow Coma Scale (GCS) score of < 8) (Jennett 1975), due to any cause, and associated with elevated intracranial pressure (ICP) $(>20$ $\mathrm{mmHg}$ ), with no previous decompressive surgery, despite other comorbidities.

\section{Types of interventions}

We assessed indomethacin compared with any control group, making sure that the comparison allowed the determination of the specific effects of indomethacin (that is, the use of indomethacin must have been the only difference between the intervention and control study arms). The intervention could have been given to participants for any length of time. Indomethacin is normally given by an intravenous loading dose followed by an infusion. In this review, any route of administration was acceptable.

\section{Types of outcome measures}

We considered all the following outcomes for the Summary of findings for the main comparison.

\section{Primary outcomes}

1. ICP (mmHg) (measured by an epidural, subdural or intraparenchymatous brain catheter with continuous monitoring). We planned to group ICP values measured at similar time points across studies.

\section{Secondary outcomes}

1. Mortality (measured at approximately one month after the start of therapy).

2. Adverse effects considered to be serious by either the patient or the clinician.

3. Disability, measured by the Glasgow Outcome Scale (GOS) (Jennett 1975), or any other measures of neurological functioning or disability, six months after the start of therapy.

4. Differences in quality of life (measured with a validated scale, such as the 36-Item Short Form Health Survey (SF-36) (Ware 1992), or the Davidson Trauma Scale (DTS) (Davidson 1997), six months after the start of therapy.

\section{Search methods for identification of studies}

In order to reduce publication and retrieval bias, we did not restrict our search by language, date or publication status.

\section{Electronic searches}

The Cochrane Injuries Group's Information Specialist ran our preliminary searches in April 2018, including one database that was not searched later:

1. Institute for Scientific Information (ISI) Web of Science: Science Citation Index Expanded (SCI-EXPANDED) (1970 to 30 April 2018).

Then Jane Falconer, Librarian at the London School of Hygiene \& Tropical Medicine, searched the following sources on 23 August 2019:

1. Cochrane Central Register of Controlled Trials (CENTRAL; 2019, Issue 8) in the Cochrane Library (23 August 2019);

2. OvidSP Medline and Epub Ahead of Print, In-Process \& Other Non-Indexed Citations and Daily, 1946 to 22 August 2019;

3. OvidSP Embase Classic + Embase, 1947 to 22 August 2019;

4. Ebsco CINAHL Plus, complete database (23 August 2019);

5. LILACS (Latin American and Caribbean Health Science Information database; 1982 to 23 August 2018);

6. OpenGrey for grey literature (www.opengrey.eu) (accessed 23 August 2019);

7. Web of Science Core Collection databases, data last updated 21 August 2019;

a. Science Citation Index Expanded (SCI-EXPANDED), 1970 onwards (accessed 23 August 2019);

b. Conference Proceedings Citation Index - Science (CPCI-S), 1990 onwards (accessed 23 August 2019); 
8. trials registers:

a. World Health Organization (WHO) International Clinical Trials Registry Platform (ICTRP) search portal (apps.who.int/ trialsearch) (accessed 23 August 2019);

b. ClinicalTrials.gov (clinicaltrials.gov) (accessed 23 August 2019).

We adapted the MEDLINE search strategy (Appendix 1 ) as necessary for each of the other databases. The added study filter was a modified version of the Ovid MEDLINE Cochrane Highly Sensitive Search Strategy for identifying randomised trials. For the Embase search strategy, we added the study design terms as used by the UK Cochrane Centre (Lefebvre 2011).

\section{Searching other resources}

We handsearched the following conference proceedings.

1. Proceedings of the Intensive Care Society and Riverside Group (London) (1997, 1998, 2001, 2002 and 2003).

2. Congreso Argentino de Terapia Intensiva (2001 to 2017, except 2002 and 2005, as conferences were not held in those years).

We checked the reference lists of relevant studies (narrative reviews and systematic reviews). We also contacted the Intensive Care Society and Riverside Group to request proceedings that were not available online.

\section{Data collection and analysis}

\section{Selection of studies}

At least two authors (Carlos Martín Saborido (CMS), Fernado G Baccaro (FB), Agustín Ciapponi (AC), Elena Garcia (EG), Gema Escobar (GE), Carlos Enrique Sánchez Martín (CESM) and Carolina Palermo (CP) ) independently screened titles and abstracts. At least two review authors (CMS, FB, AC, GE, CESM, and CP) independently assessed full-text articles of potentially eligible studies. If there was no consensus between the two authors involved in the screening or in the assessment of the full-texts, Jesús López Alcalde (JLA) intervened to solve the disagreement. We used Covidence to implement the selection process (Covidence 2017). We documented the reasons for the exclusion of the full-text articles we assessed.

\section{Data extraction and management}

We could not extract data because we did not find any relevant studies. For each included study, we had planned to extract details of the population, setting, methods, intervention and comparator, outcomes, funding, and declaration of interests. We had also planned to populate a table of 'Characteristics of included studies' and to look for retraction statements regarding each included study.

\section{Assessment of risk of bias in included studies}

We could not assess risk of bias because we did not find any relevant studies. We had intended that two review authors would independently assess risk of bias for each study using the criteria outlined in the Cochrane Handbook for Systematic Reviews of Interventions (Higgins 2011a). We had planned to resolve any disagreements by discussion or by involving another review author.

\section{Measures of treatment effect}

For continuous data, we had planned to compare the values in the treatment and control groups at final follow-up. We had expected to use mean differences (MDs) with 95\% confidence intervals (Cls) as summary statistics. If studies had used different measurement instruments or units to measure an outcome, we had planned to use the standardised mean difference (SMD).

If dichotomous data had been presented, we would have calculated risk ratios (RR) with $95 \% \mathrm{Cls}$. Additionally, we would have transformed the GOS and GCS data into the dichotomous outcomes of 'favourable' (moderate disability, good recovery; GOS 4 and 5) and 'unfavourable' (death, vegetative state, severe disability; GOS 1 to 3) (Brazinova 2010; Jennett 1975).

If some studies had reported an outcome as a dichotomous measure and others had used a continuous measure of the same construct, we would have converted results from a RR to a SMD, provided that we could have assumed that the underlying continuous measure had an approximately normal distribution.

\section{Unit of analysis issues}

The unit of analysis would have been the person with severe brain trauma. If we had included cluster-RCTs in the analysis, we had planned to reanalyse these studies by calculating their sample size with an estimate of the intracluster coefficient (ICC), which we would have estimated from similar studies if the ICC had not been given (Higgins 2011b).

\section{Dealing with missing data}

Where necessary, we had planned to contact the corresponding authors of included studies up to three times to request unreported data.

If studies had not reported the standard deviation (SD), we had planned to calculate it from $\mathrm{P}$ values, $\mathrm{t}$ values, $\mathrm{Cls}$, or standard errors (Higgins 2011c). If this information had not been reported, or was unavailable, we would have borrowed the SD from the study with the highest SD for that outcome. To assess the effect of missing data on the analysis, we had planned to conduct a sensitivity analysis for that outcome by showing our results with the borrowed $\mathrm{SD}$ versus the lowest SD.

If outcome data had been reported only as a median or range, we would have reported the information in additional tables.

If a study had reported outcomes only for the participants who completed the trial, or only for participants who followed the protocol, we would have asked the study authors to provide additional information to allow us to conduct meta-analyses using the intention-to-treat approach. We would have described missing data and dropouts for each included study in the 'Risk of bias' table, reporting the reasons, number, and characteristics of dropouts. Also, we would have discussed the extent to which the missing data could have altered the results. We had planned to conduct sensitivity analyses to assess the effect of missing dichotomous data on our primary meta-analysis, by assuming firstly that all missing data were successes, and secondly that all missing data were failures (best- versus worst-case scenario analyses). 
We had expected to impute the missing data with replacement values, and to treat them as they were observed (last observation carried forward (LOCF) or imputing the mean). If levels of missing data in a study had been very high (e.g. $80 \%$ ), we would not have included that study in the analysis.

We had planned to explore the impact of including studies with missing data in the overall assessment of the treatment effect by using 'worst-case' and 'best-case' scenario sensitivity analyses. We would have addressed the potential impact of missing data on the findings of the review in the discussion section.

\section{Assessment of heterogeneity}

We could not assess heterogeneity because we did not find any studies. We had planned to explore clinical and statistical sources of heterogeneity among the studies (Deeks 2011). Clinical sources could have included comorbidity, brain injury severity, and type of indomethacin administration protocols. We would have assessed statistical heterogeneity using the $\mathrm{I}^{2}$ statistic and the $\mathrm{Chi}^{2}$ test. We would have considered a result to be statistically significant if $P$ $<0.1$. We had planned to consider values of $1^{2}$ over $60 \%$ to be an indication of 'moderate' heterogeneity and values above $85 \%$ to represent 'considerable' heterogeneity. We had planned not to carry out a meta-analysis if $\mathrm{I} 2$ was considerable, and would have documented the rationale for our decision.

\section{Assessment of reporting biases}

We could not assess reporting bias because we did not find any studies. If we had included at least 10 studies in the analysis, we had planned to create a funnel plot. Funnel plot asymmetry can be due to publication bias, but it can also be due to a real relationship between trial size and effect size, such as when larger trials have lower compliance and compliance is positively related to effect size. In general, asymmetry may be due to selection biases (publication bias, delayed publication bias, location biases, selective outcome reporting), poor methodological quality leading to spuriously inflated effects in smaller studies (poor methodological design, inadequate analysis, fraud), true heterogeneity or chance (Egger 1997). We had planned to use the test proposed by Egger 1997 to test for funnel plot asymmetry (Sterne 2011).

\section{Data synthesis}

We could not perform data synthesis because we did not find any studies. If we had found at least two studies that were sufficiently homogenous in terms of participants, interventions and outcomes, we had planned to synthesise results in a meta-analysis. We would have performed statistical analysis using the Cochrane software, Review Manager (Review Manager 2014). Because we had assumed that clinical heterogeneity was very likely to impact on the results of our review, given the nature of the intervention included, we had planned to report results from the random-effects model.

\section{Subgroup analysis and investigation of heterogeneity}

We could not perform subgroup analysis or investigate heterogeneity because we did not find any studies.

In the protocol for this review, we had planned to conduct subgroup analyses classifying the trials as follows:

1. severity of traumatic brain injury (mild and moderate (GCS 9 to 15) versus severe (GCS 3 to 8$)$ );

2. comorbidity (severe comorbidity versus non-severe comorbidity);

3. different indomethacin administration protocols.

\section{Sensitivity analysis}

We could not perform sensitivity analysis because we did not find any studies.

At the protocol stage, we had planned to conduct sensitivity analyses to assess the impact of the following factors on the results of the primary analyses:

1. risk of bias (allocation concealment and sequence generation): we had planned to restrict the analysis to only studies with low risk of selection bias;

2. missing participant data: we had planned to explore the impact of including studies with high levels of missing data.

\section{RE S U L T S}

\section{Description of studies}

\section{Results of the search}

Electronic searches yielded 8648 records after removal of duplicates. We examined titles and abstracts and retrieved 21 full-text articles for further examination. We did not identify any studies that met the eligibility criteria. We did not find any further eligible studies, either complete or ongoing, through searching other sources (checking the abstracts of relevant conferences, and checking reference lists of key documents). We did not identify any ongoing trials. The study flow diagram (Figure 1) follows the template described in the PRISMA statement (Liberati 2009). 
Figure 1. Study flow diagram

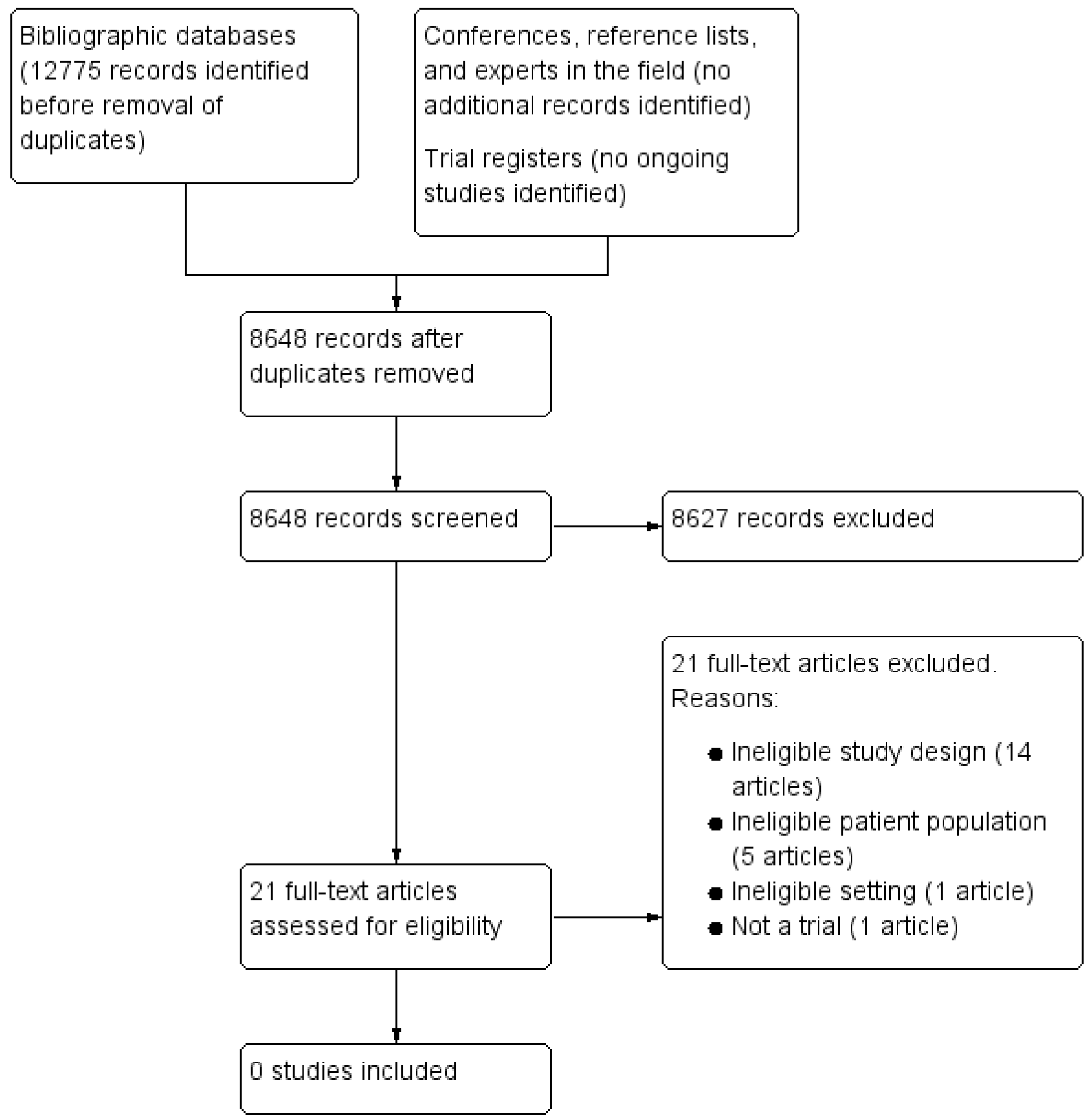

\section{Included studies}

We found no eligible studies for this review.

\section{Excluded studies}

We excluded all 21 records that we retrieved for full-text assessment of eligibility. We summarised the reasons for their exclusion in the flow diagram (Figure 1) and in the Characteristics of excluded studies table. The most frequent reason for exclusion of potentially relevant studies was the absence of randomisation (the most frequent design was the uncontrolled before-after study) (Biestro 1995; Blaser 1988; Clemmesen 1997; Dahl 1996; Dohi 2006; Godoy
2012; Godoy 2014; Imberti 2005; Jensen 1990; Jensen 1991; Jensen 1992; Muehlschlegel 2013; Nitter 1995; Puppo 2007).

\section{Risk of bias in included studies}

No studies met the eligibility criteria, so we could not assess risk of bias.

\section{Effects of interventions}

See: Summary of findings for the main comparison Indomethacin for controlling intracranial hypertension secondary to severe traumatic brain injury 
We did not find any trials that assessed the effects of indomethacin in controlling intracranial hypertension secondary to severe TBI.

\section{DISCUSSION}

\section{Summary of main results}

This review did not find any eligible studies, either completed or ongoing. Consequently, we could not determine the effects of indomethacin in controlling intracranial hypertension secondary to severe traumatic brain injury (TBI).

\section{Overall completeness and applicability of evidence}

\section{Completeness of the evidence}

No trials met our inclusion criteria. Thus, the evidence base for the effects of indomethacin in controlling intracranial hypertension secondary to severe $\mathrm{TBI}$ is incomplete. Although electronic searches retrieved a considerable number of records, none of the studies identified met the inclusion criteria because most had a controlled before-after study design.

It is possible that the setting of our research question (emergency departments) might mean that trialists would not choose RCTs as their preferred design, and this could explain why we found several uncontrolled before-after studies.

\section{Applicability of the evidence}

We could not assess the applicability of the evidence of this review as we did not find any eligible studies.

\section{Quality of the evidence}

We identified no eligible studies for this review. Thus, we were unable to comment on the quality of the evidence for this clinical question.

\section{Potential biases in the review process}

Our searches were extensive in order to reduce the risk of publication bias and to identify as much relevant evidence as possible. Our searches were carefully designed by the Information Specialist of the Cochrane Injuries Group and the Librarian at the London School of Hygiene \& Tropical Medicine, without any restrictions on language or date of publication. However, we did not contact pharmaceutical companies, which might have identified potentially eligible study data that were unpublished. We could not screen all conference proceedings for the Proceedings of the Intensive Care Society and Riverside Group as they were not available through their website. Similarly, conference proceedings for the Congreso Argentino de Terapia Intensiva were only available for the years 2001 to 2017 (except 2002 and 2005, as conferences were not held in those years).

\section{Agreements and disagreements with other studies or reviews}

We found no randomised studies conducted on this topic, but we did find a review that assessed the use of indomethacin and its effects on intracranial pressure (ICP) in patients with neurological illness (Sader 2015). This review defined eligible studies as being prospective, with five or more participants who had a documented response to indomethacin, and with trial reports published in English. Its authors identified two RCTs where the participants had brain tumours but not TBI, and 10 prospective cohort studies investigating people with TBI. Sader 2015 stated that nine out of 10 studies documented a decrease in ICP with indomethacin administration, and concluded that evidence provided by these studies suggested that indomethacin may reduce ICP in the severe TBI population. However, studies which did not show an effect of indomethacin on ICP were not eligible for inclusion in the review, so indomethacin for ICP control remains experimental and further prospective studies are needed (Sader 2015). Only two studies included in the Sader 2015 review reported adverse events related to indomethacin administration: one was a study of people with severe $\mathrm{TBI}$, where there was a critical reduction in jugular venous oxygen saturation in two of the six patients treated with indomethacin; and the other was a study of idiopathic intracranial hypertension which described dizziness in four patients.

\section{AUTHORS' CONCLUSIONS}

\section{Implications for practice}

We found no randomised controlled trials (RCTs), either completed or ongoing, that assessed the effects of indomethacin in controlling intracranial hypertension secondary to severe traumatic brain injury (TBI). Thus, we could not draw conclusions about the impact of indomethacin on intracranial pressure, mortality rates, quality of life, disability or adverse effects.

This absence of evidence should not be interpreted as evidence of no effect for indomethacin in controlling intracranial hypertension secondary to severe TBI. It means that we did not identify any evidence from RCTs which could inform practice.

\section{Implications for research}

This is an 'empty review', that is, a review that has found no eligible studies for inclusion. This highlights the need for rigorous RCTs to determine the effects of indomethacin in controlling intracranial hypertension secondary to severe TBI.

Future trials should be rigorous in design and delivery. Researchers should report the trial according to relevant guidelines, such as CONSORT (CONsolidated Standards of Reporting Trials 2010) (Schulz 2010), TIDieR (template for intervention description and replication) (Hoffmann 2014), and reporting guidelines for health equity concerns in RCTs (Welch 2017).

The RCT should evaluate the effect of indomethacin on patientrelevant outcomes. To our knowledge there is no 'core outcome set' (COS) for RCTs in this area. A COS should be developed with the methodology proposed in the COMET Handbook (Williamson 2017).

A rigorous evaluation of indomethacin is required to evaluate benefits and harms in patients with TBI. The evaluation of harms will require an adequately powered study.

\section{ACKNOWLEDGEMENTS}

We would like to acknowledge Marina Romano for her support in the development of the protocol.

We would like to thank the peer reviewers: Daniel Godoy, Jordan Bonomo, Sarah Tanveer, and consumer reviewer: Jo Weldon. 
This project was supported by the UK National Institute for Health Research (NIHR), through Cochrane Infrastructure funding to the Cochrane Injuries Group. The views and opinions expressed are those of the authors and do not necessarily reflect those of the Systematic Reviews Programme, NIHR, NHS or the Department of Health. 


\section{RE F E R E N C E S}

\section{References to studies excluded from this review}

Biestro 1995 \{published data only\}

Biestro AA, Alberti RA, Soca AE, Cancela M, Puppo CB, Borovich $B$. Use of indomethacin in brain-injured patients with cerebral perfusion pressure impairment: preliminary report. Journal of Neurosurgery 1995;83(4):627-30.

\section{Blaser 1988 \{published data only\}}

Blaser KU, Lammle B. Acute hyperkalemia and non-oliguric renal failure during treatment with indomethacin, allopurinol, nifedipine, hydrochlorothiazide/amiloride, trimethoprime/ sulfamethoxazole and acetylsalicylic acid [Akute hyperkaliamie und nichtoligurische niereninsuffizienz unter Indomethacin, allopurinol, nifedipin, hydrochlorothiazid/amilorid, trimethoprim/sulfamethoxazol und azetylsalizylsaure]. Schweizerische Rundschau für Medizin Praxis 1988;77(3):38-40.

\section{Clemmesen 1997 \{published data only\}}

Clemmesen JO, Hansen BA, Larsen FS. Indomethacin normalizes intracranial pressure in acute liver failure: a twentythree-year-old woman treated with indomethacin. Hepatology 1997;26(6):1423-5.

\section{Cotton 2002 \{published data only\}}

Cotton RB. Indomethacin: continuous versus bolus administration. Acta Paediatrica 2002;91:369-70.

\section{Dahl 1996 \{published data only\}}

Dahl B, Bergholt B, Cold GE, Astrup J, Mosdal B, Jensen K, et al. $\mathrm{CO} 2$ and indomethacin vasoreactivity in patients with head injury. Acta Neurochirurgica 1996;138(3):265-73.

\section{Dohi 2006 \{published data only\}}

Dohi K, Jimbo H, Ikeda Y, Fujita S, Ohtaki H, Shioda S, et al. Pharmacological brain cooling with indomethacin in acute hemorrhagic stroke: antiinflammatory cytokines and antioxidative effects. Acta Neurochirurgica. Supplement 2006;96:57-60.

\section{Fan 2010 \{published data only\}}

Fan JL, Burgess KR, Thomas KN, Peebles KC, Lucas SJ, Lucas RA, et al. Influence of indomethacin on ventilatory and cerebrovascular responsiveness to $\mathrm{CO} 2$ and breathing stability: the influence of PCO2 gradients. American Journal of Physiology. Regulatory, Integrative and Comparative Physiology 2010;298(6):R1648-58

\section{Fan 2011 \{published data only\}}

Fan JL, Burgess KR, Thomas KN, Peebles KC, Lucas SJ, Lucas RA, et al. Influence of indomethacin on the ventilatory and cerebrovascular responsiveness to hypoxia. European Journal of Applied Physiology 2011;111(4):601-10.

\section{Godoy 2012 \{published data only\}}

Godoy DA, Rabinstein AA, Biestro A, Ainslie PN, Di Napoli M. Effects of indomethacin test on intracranial pressure and cerebral hemodynamics in patients with refractory intracranial hypertension: a feasibility study. Neurosurgery 2012;71(2):245-57.

\section{Godoy 2014 \{published data only\}}

Godoy DA, Alvarez E, Manzi R, Pinero G, Di Napoli M. The physiologic effects of indomethacin test on CPP and ICP in severe traumatic brain injury (STBI). Neurocritical Care 2014;20(2):230-9.

\section{Hammerman 1995 \{published data only\}}

Hammerman C, Glaser J, Schimmel MS, Ferber B, Kaplan M, Eidelman Al. Continuous versus multiple rapid infusions of indomethacin: effects on cerebral blood flow velocity. Pediatrics 1995;95(2):244-8

\section{Imberti 2005 \{published data only\}}

Imberti R, Fuardo M, Bellinzona G, Pagani M, Langer M. The use of indomethacin in the treatment of plateau waves: effects on cerebral perfusion and oxygenation. Journal of Neurosurgery 2005;102(3):455-9.

\section{Jensen 1990 \{published data only\}}

Jensen K, Ohrstrom J, Cold GE, Astrup J. Indomethacin in severe cerebral contusions with intracranial hypertension [L'indometacine dans les contusions cerebrales severes avec hypertension intracranienne]. Cahiers d'Anesthesiologie 1990;38(8):530-2.

\section{Jensen 1991 \{published data only\}}

Jensen K, Ohrstrom J, Cold GE, Astrup J. The effects of indomethacin on intracranial pressure, cerebral blood flow and cerebral metabolism in patients with severe head injury and intracranial hypertension. Acta Neurochirurgica 1991;108(3-4):116-21.

\section{Jensen 1992 \{published data only\}}

Jensen K, Ohrstrom J, Cold GE, Astrup J. Indomethacin (Confortid) in severe head injury and elevated intracranial pressure (ICP). Neurotraumatology: Progress and Perspectives. Acta Neurochirurgica. Vol. 55, Vienna: Springer, 1992:47-8.

\section{Muehlschlegel 2013 \{published data only\}}

Muehlschlegel S, Carandang R, Ouillette C, Hall W, Anderson F, Goldberg R. Frequency and impact of intensive care unit complications on moderate-severe traumatic brain injury: early results of the outcome prognostication in traumatic brain injury (OPTIMISM) study. Neurocritical Care 2013;18(3):318-31.

NCT01280006 \{published data only\}

NCT01280006. Effect of selective and nonselective cyclooxygenase enzyme inhibition on arterial blood pressure and cerebral blood flow with exposure to intermittent hypoxia in humans. clinicaltrials.gov/show/NCT01280006 (first received 18 January 2011).

\section{Nitter 1995 \{published data only}

Nitter WH, Johnsen LF, Eriksen M. Acute effects of indometacin on cerebral blood flow in man. Pharmacology 1995;51(1):48-55 
Puppo 2007 \{published data only\}

Puppo C, Lopez L, Farina G, Caragna E, Moraes L, Iturralde A, et al. Indomethacin and cerebral autoregulation in severe head injured patients: a transcranial Doppler study. Acta Neurochirurgica. Austria, 2007; Vol. 149, issue 2:139-49.

\section{Rasmussen 2004 \{published data only\}}

Rasmussen M, Tankisi A, Cold GE. The effects of indomethacin on intracranial pressure and cerebral haemodynamics in patients undergoing craniotomy: a randomised prospective study. Anaesthesia 2004;59(3):229-36.

Smirl 2014 \{published data only\}

Smirl JD, Tzeng YC, Monteleone BJ, Ainslie PN. Influence of cerebrovascular resistance on the dynamic relationship between blood pressure and cerebral blood flow in humans. Journal of Applied Physiology 2014;116(12):1614-22.

\section{Additional references}

\section{Alarcon 2017}

Alarcon JD, Rubiano AM, Okonkwo DO, Alarcon J, MartinezZapata MJ, Urrutia G, et al. Elevation of the head during intensive care management in people with severe traumatic brain injury. Cochrane Database of Systematic Reviews 2017, Issue 12. [DOI: 10.1002/14651858.CD009986.pub2]

\section{Andelic 2012}

Andelic N, Anke A, Skandsen T, Sigurdardottir S, Sandhaug M, Ader T, et al. Incidence of hospital-admitted severe traumatic brain injury and in-hospital fatality in Norway: a national cohort study. Neuroepidemiology 2012;38(4):259-67.

\section{Bergen 2008}

Bergen G, Chen LH, Warner M, Fingerhut LA. Injury in the United States: 2007 Chartbook. Hyattsville (MD): National Center for Health Statistics, 2008.

\section{Bratton 2007}

Bratton SL, Chestnut RM, Ghajar J, McConnell Hammond FF, Harris OA, Hartl R, et al. Guidelines for the management of severe traumatic brain injury. VIII: Intracranial pressure thresholds. Journal of Neurotrauma 2007;24 Suppl 1:S55-8. [PUBMED: 17511546]

\section{Brazinova 2010}

Brazinova A, Mauritz W, Leitgeb J, Wilbacher I, Majdan M, Janciak I, et al. Outcomes of patients with severe traumatic brain injury who have Glasgow Coma Scale scores of 3 or 4 and are over 65 years old. Journal of Neurotrauma 2010;27(9):1549-55.

\section{CDC 2015}

Centers for Disease Control and Prevention, National Center for Injury Prevention and Control, Division of Unintentional Injury Prevention. Report to Congress on Traumatic Brain Injury in the United States: Epidemiology and Rehabilitation. www.cdc.gov/traumaticbraininjury/pdf/ TBI_Report_to_Congress_Epi_and_Rehab-a.pdf. Atlanta, (accessed 16 March 2018).

\section{Chelly 2017}

Chelly H, Bahloul M, Ammar R, Dhouib A, Mahfoudh KB, Boudawara MZ, et al. Clinical characteristics and prognosis of traumatic head injury following road traffic accidents admitted in ICU "analysis of 694 cases". European Journal of Trauma and Emergency Surgery 2019;45(2):245-53. [DOI: 10.1007/ s00068-017-0885-4]

\section{Covidence 2017 [Computer program]}

Veritas Health Innovation. Covidence. Version accessed 4 October 2019. Melbourne, Australia: Veritas Health Innovation.

\section{Davanzo 2017}

Davanzo JR, Sieg EP, Timmons SD. Management of traumatic brain injury. The Surgical Clinics of North America 2017;97(6):1237-53. [PUBMED: 29132507]

\section{Davidson 1997}

Davidson JR, Book SW, Colket JT, Tupler LA, Roth S, David D, et al. Assessment of a new self-rating scale for post-traumatic stress disorder. Psychological Medicine 1997;27(1):153-60. [PUBMED: 9122295]

\section{Deeks 2011}

Deeks JJ, Higgins JP, Altman DG (editors). Chapter 9: Analysing data and undertaking meta-analyses. In: Higgins JP, Green S (editors). Cochrane Handbook for Systematic Reviews of Interventions Version 5.1.0 (updated March 2011). The Cochrane Collaboration, 2011. Available from www.handbook.cochrane.org.

\section{Donkin 2010}

Donkin JJ, Vink R. Mechanisms of cerebral edema in traumatic brain injury: therapeutic developments. Current Opinion in Neurology 2010;23(3):293-9. [PUBMED: 20168229]

\section{Egger 1997}

Egger M, Davey Smith G, Schneider M, Minder C. Bias in meta-analysis detected by a simple, graphical test. BMJ 1997;315:629-34.

\section{El-Mashad 2017}

El-Mashad AE, El-Mahdy H, El Amrousy D, Elgendy M. Comparative study of the efficacy and safety of paracetamol, ibuprofen, and indomethacin in closure of patent ductus arteriosus in preterm neonates. European Journal of Pediatrics 2017;176(2):233-40. [PUBMED: 28004188]

\section{Girgis 2013}

Girgis H, Palmier B, Croci N, Soustrat M, Plotkine M, MarchandLeroux $C$. Effects of selective and non-selective cyclooxygenase inhibition against neurological deficit and brain oedema following closed head injury in mice. Brain Research 2013;1491:78-87.

\section{Godoy 2005}

Godoy DA, Biestro A, Puppo C. Does indomethacin cause cerebral ischemia?. Acta Anaesthesiologica Scandinavica 2005;49(10):1577-8. [PUBMED: 16223416] 


\section{Godoy 2017}

Godoy DA, Suarez PD, Moscote-Salazar LR, Napoli MD. Side effects of indomethacin in refractory post-traumatic intracranial hypertension: a comprehensive case study and review. Bulletin of Emergency and Trauma 2017;5(3):143-51. [PUBMED: 28795057]

\section{Grände 2006}

Grände PO. The "Lund Concept" for the treatment of severe head trauma - physiological principles and clinical application. Intensive Care Medicine 2005;32(10):1475-84.

\section{Higgins 2011a}

Higgins JP, Altman DG, Sterne JA, editor(s). Chapter 8: Assessing risk of bias in included studies. In: Higgins JP, Green $S$, editor(s). Cochrane Handbook for Systematic Reviews of Interventions Version 5.1.0 (updated March 2011). The Cochrane Collaboration, 2011. Available from handbook.cochrane.org.

\section{Higgins 2011b}

Higgins JP, Deeks JJ, Altman DG, editor(s). Chapter 16: Special topics in statistics. In: Higgins JP, Green S, editor(s). Cochrane Handbook for Systematic Reviews of Interventions Version 5.1.0 (updated March 2011). The Cochrane Collaboration, 2011. Available from www.handbook.cochrane.org.

\section{Higgins 2011c}

Higgins JP, Deeks JJ, editor(s). Chapter 7: Selecting studies and collecting data. In: Higgins JP, Green S, editor(s). Cochrane Handbook for Systematic Reviews of Interventions Version 5.1.0 (updated March 2011). The Cochrane Collaboration, 2011. Available from www.handbook.cochrane.org.

\section{Hoffmann 2014}

Hoffmann TC, Glasziou PP, Boutron I, Milne R, Perera R, Moher D, et al. Better reporting of interventions: template for intervention description and replication (TIDieR) checklist and guide. BMJ (Clinical Research Ed.) 2014;348:g1687.

\section{Jennett 1975}

Jennett B, Bond M. Assessment of outcome after severe brain damage. Lancet 1975;1:480-4.

\section{Lefebvre 2011}

Lefebvre C, Manheimer E, Glanville J. Chapter 6: Searching for studies. In: Higgins JP, Green S, editor(s). Cochrane Handbook for Systematic Reviews of Interventions Version 5.1.0 (updated March 2011). The Cochrane Collaboration, 2011. Available from handbook.cochrane.org.

\section{Liberati 2009}

Liberati A, Altman DG, Tetzlaff J, Mulrow C, Gotzsche PC, Ioannidis JP, et al. The PRISMA statement for reporting systematic reviews and meta-analyses of studies that evaluate health care interventions: explanation and elaboration. PLOS Medicine 2009;6(7):e1000100.

\section{Littlejohns 2005}

Littlejohns L, Bader MK. Prevention of secondary brain injury: targeting technology. AACN Advanced Critical Care 2005;16(4):501-14.

\section{Medscape monograph 2019}

Medscape Drugs \& Diseases. Medscape prescription drug monographs. reference.medscape.com/drug/indocin-tivorbexindomethacin-343290\#4 (accessed 9 August 2019).

\section{Meyer 2010}

Meyer MJ, Megyesi J, Meythaler J, Murie-Fernandez M, Aubut JA, Foley $\mathrm{N}$, et al. Acute management of acquired brain injury part II: an evidence-based review of pharmacological interventions. Brain Injury 2010;24(5):706-21.

\section{Muzevic 2013}

Muzevic D, Splavski B. The Lund concept for severe traumatic brain injury. Cochrane Database of Systematic Reviews 2013, Issue 12. [DOI: 10.1002/14651858.CD010193.pub2]

\section{NICE 2014}

National Institute for Health and Care Excellence. Head injury: Triage, assessment, investigation and early management of head injury in children, young people and adults. NICE guidelines [CG176]. Published date: January 2014. www.nice.org.uk/guidance/cg176 (accessed 21 December 2017).

\section{Ponsford 2013}

Ponsford JL, Spitz G, Cromarty F, Gifford D, Attwood D. Costs of care after traumatic brain injury. Journal of Neurotrauma 2013;30(17):1498-505.

\section{Pun 2017}

Pun M. Indomethacin on extra-cranial cerebral arterial vasomotion: beyond cyclooxygenase-prostaglandin inhibition. Journal of Physiology 2017; Vol. 595, issue 11:3671. [PUBMED: 28568769]

\section{Reilly 2007}

Reilly P. The impact of neurotrauma on society: an international perspective. Progress in Brain Research 2007;161:3-9.

\section{Review Manager 2014 [Computer program]}

Nordic Cochrane Centre, The Cochrane Collaboration. Review Manager 5 (RevMan 5). Version 5.3. Copenhagen: Nordic Cochrane Centre, The Cochrane Collaboration, 2014.

\section{Sader 2015}

Sader N, Zeiler FA, Gillman LM, West M, Kazina CJ. Indomethacin for control of ICP. Neurocritical Care 2015;22(3):437-49.

\section{Schulz 2010}

Schulz KF, Altman DG, Moher D. CONSORT 2010 statement: updated guidelines for reporting parallel group randomized trials. Annals of Internal Medicine 2010;152(11):726-32.

\section{Sterne 2011}

Sterne JA, Egger M, Moher D, editor(s). Chapter 10: Addressing reporting biases. In: Higgins JP, Green S, editor(s). Cochrane Handbook for Systematic Reviews of Interventions Version 5.1.0 (updated March 2011). The Cochrane Collaboration, 2011. Available from www.handbook.cochrane.org. 


\section{Sullivan 2000}

Sullivan J. Positioning of patients with severe traumatic brain injury: research-based practice. Journal of Neuroscience Nursing 2000;32(4):204-9.

\section{Ware 1992}

Ware JE Jr, Sherbourne CD. The MOS 36-item short-form health survey (SF-36). I. Conceptual framework and item selection. Medical care 1992;30(6):473-83. [PUBMED: 1593914]

\section{Welch 2017}

Welch VA, Norheim OF, Jull J, Cookson R, Sommerfelt $\mathrm{H}$, Tugwell P. CONSORT-Equity 2017 extension and elaboration for better reporting of health equity in randomised trials. BMJ (Clinical Research Ed.) 2017;359:j5085.

\section{CHARACTERISTICS OF STUDIES}

Characteristics of excluded studies [ordered by study ID]

\section{Williamson 2017}

Williamson PR, Altman DG, Bagley H, Barnes KL, Blazeby JM, Brookes ST, et al. The COMET Handbook: version 1.0. Trials 2017;18(Suppl 3):280.

\section{References to other published versions of this review \\ Baccaro 2015}

Baccaro FG, Romano M, Ciapponi A, López-Alcalde J. Indomethacin in controlling intracranial hypertension secondary to severe traumatic brain injury. Cochrane Database of Systematic Reviews 2015, Issue 6. [DOI: 10.1002/14651858.CD011725]

\begin{tabular}{|c|c|}
\hline Study & Reason for exclusion \\
\hline Biestro 1995 & Not a randomised controlled trial \\
\hline Blaser 1988 & Not a randomised controlled trial \\
\hline Clemmesen 1997 & Not a randomised controlled trial \\
\hline Cotton 2002 & Not a randomised controlled trial, but a comment \\
\hline Dahl 1996 & Not a randomised controlled trial \\
\hline Dohi 2006 & Not a randomised controlled trial \\
\hline Fan 2010 & Participants did not have TBI, but were healthy adults \\
\hline Fan 2011 & Participants did not have TBI, but were healthy adults \\
\hline Godoy 2012 & Not a randomised controlled trial \\
\hline Godoy 2014 & Not a randomised controlled trial \\
\hline Hammerman 1995 & Participants did not have $\mathrm{TBI}$, but were premature infants \\
\hline Imberti 2005 & Not a randomised controlled trial \\
\hline Jensen 1990 & Not a randomised controlled trial \\
\hline Jensen 1991 & Not a randomised controlled trial \\
\hline Jensen 1992 & Not a randomised controlled trial \\
\hline Muehlschlegel 2013 & Not a randomised controlled trial \\
\hline NCT01280006 & Ineligible setting (laboratory experiment) \\
\hline Nitter 1995 & Not a randomised controlled trial \\
\hline
\end{tabular}




\begin{tabular}{ll}
\hline Study & Reason for exclusion \\
\hline Puppo 2007 & Not a randomised controlled trial \\
\hline Rasmussen 2004 & Participants did not have TBI, but were people with brain tumours \\
\hline Smirl 2014 & Participants did not have TBI, but were healthy subjects \\
\hline
\end{tabular}

TBI: traumatic brain injury

\section{APPENDICES}

\section{Appendix 1. Search strategies}

\section{Wiley Cochrane Central Register of Controlled Trials}

\#1 MeSH descriptor: [Indomethacin] explode all trees (2514)

\#2 MeSH descriptor: [Anti-Inflammatory Agents, Non-Steroidal] this term only (6320)

\#3 (indomet?acin`):ti,ab,kw (3167)

\#4 (indocin):ti,ab,kw (8)

\#5 (indocid):ti,ab,kw (37)

\#6 (tivorbex):ti,ab,kw (0)

\#7 (ketorolac):ti,ab,kw (2460)

\#8 (IDM):ti,ab,kw (73)

\#9 (nsaid?):ti,ab,kw (6069)

\#10 (anti-inflammator $\left.{ }^{\star}\right): t i, a b, k w ~(26766)$

$\# 11 \# 1$ or \#2 or \#3 or \#4 or \#5 or \#6 or \#9 or \#10 (31613)

\#12 MeSH descriptor: [Brain Ischemia] explode all trees (3230)

\#13 MeSH descriptor: [Intracranial Pressure] this term only (335)

\#14 MeSH descriptor: [Cerebrovascular Circulation] explode all trees (1525)

\#15 MeSH descriptor: [Brain Edema] this term only (185)

\#16 MeSH descriptor: [Intracranial Hypertension] explode all trees (180)

\#17 MeSH descriptor: [Craniocerebral Trauma] explode all trees (3134)

\#18 MeSH descriptor: [Decompression, Surgical] this term only (482)

\#19 MeSH descriptor: [Decompressive Craniectomy] this term only (20)

\#20 MeSH descriptor: [Monitoring, Physiologic] this term only (2152)

\#21 MeSH descriptor: [Hemodynamic Monitoring] this term only (9)

\#22 MeSH descriptor: [Monitoring, Intraoperative] explode all trees (1556)

\#23 MeSH descriptor: [Neurophysiological Monitoring] explode all trees (44)

\#24 ((intracranial or cerebr* or brain) near/3 hypertens $\left.{ }^{\star}\right): t i, a b, k w ~(977)$ 
\#25 (brain near/3 (isch?emia or pressure or perfusion or oedema or edema or injur ${ }^{\star}$ or trauma* or ICP or CPP)):ti,ab,kw (12455)

\#26 ((cerebral or intracranial) near/3 (isch?emia or pressure or perfusion or oedema or edema or injur* or trauma* or ICP or CPP or vasoconstrict*)):ti,ab,kw (4251)

$\# 27 \# 12$ or \#13 or \#14 or \#15 or \#16 or \#17 or \#18 or \#19 or \#20 or \#21 or \#22 or \#23 or \#24 or \#25 or \#26 (22566)

\#28 \#11 and \#27 (344)

OvidSP Medline and Epub Ahead of Print, In-Process \& Other Non-Indexed Citations and Daily

1 exp Indomethacin/ (29933)

2 Anti-Inflammatory Agents, Non-Steroidal/ (65004)

3 indomet?acin*.ti,ab. (36087)

4 indocin.ti,ab. (46)

5 indocid.ti,ab. (75)

6 tivorbex.ti,ab. (1)

7 ketorolac.ti,ab. (2754)

8 IDM.ti,ab. (546)

9 nsaid?.ti,ab. (23706)

10 anti-inflammator ${ }^{\star} . t i, a b .(146032)$

11 or/1-10 [INDOMETHACIN] (225782)

12 exp Brain Ischemia/ (103084)

13 Intracranial Pressure/ (14699)

14 exp Cerebrovascular Circulation/ (53866)

15 Brain Edema/ (14186)

16 exp Intracranial Hypertension/ (9610)

17 exp Craniocerebral Trauma/ (152505)

18 decompression, surgical/ (14782)

19 decompressive craniectomy/ (1202)

20 monitoring, physiologic/ (53061)

21 hemodynamic monitoring/ (127)

22 exp monitoring, intraoperative/ (19246)

23 exp neurophysiological monitoring/ (1307)

24 ((intracranial or cerebr* or brain) adj3 hypertens $\left.{ }^{\star}\right)$.ab,ti. (10713)

25 (brain adj3 (isch?emia or pressure or perfusion or oedema or edema or injur* or trauma* or ICP or CPP)).ab,ti. (85746)

26 ((cerebral or intracranial) adj3 (isch?emia or pressure or perfusion or oedema or edema or injur ${ }^{\star}$ or trauma* or ICP or CPP or vasoconstrict*)).ab,ti. (68725)

\section{7 or/12-26 [INTRACRANIAL HYPERTENSION] (452198)}

28 randomi?ed.ab,ti. (582266)

29 randomized controlled trial.pt. (487883) 
30 controlled clinical trial.pt. (93234)

31 placebo.ab. (200192)

32 exp Clinical Trials as Topic/ (329437)

33 randomly.ab. (316700)

34 trial.ti. (203504)

35 comparative study/ (1838023)

36 or/28-35 [RANDOMISED CONTROLLED TRIALS] (2940717)

3711 and 27 and 36 (650)

38 remove duplicates from 37 (649)

39 limit 38 to medline (604)

4038 not 39 (45)

\section{OvidSP Embase Classic + Embase}

1 indometacin/ (78844)

2 nonsteroid antiinflammatory agent/ (119067)

3 indomet?acin*.ti,ab. (44146)

4 indocin.ti,ab. (84)

5 indocid.ti,ab. (127)

6 tivorbex.ti,ab. (2)

7 ketorolac.ti,ab. (4141)

8 IDM.ti,ab. (789)

9 nsaid?.ti,ab. (41423)

10 anti-inflammator ${ }^{\star} . t i, a b$. (206275)

11 or/1-10 (370822)

12 exp brain ischemia/ (177720)

13 intracranial pressure/ (24357)

14 exp brain circulation/ (24488)

15 brain edema/ (33389)

16 exp intracranial hypertension/ (19707)

17 head injury/ (52449)

18 exp brain injury/ (182521)

19 second impact syndrome/ (148)

20 exp skull injury/ (30094)

21 decompression surgery/ (18338)

22 brain decompression/ (2037)

23 decompressive craniectomy/ (3589) 
24 exp physiologic monitoring/ (5795)

25 hemodynamic monitoring/ (15388)

26 exp intraoperative monitoring/ (1783)

27 ((intracranial or cerebr ${ }^{\star}$ or brain) adj3 hypertens $\left.{ }^{\star}\right) . a b, t i . ~(16283)$

28 (brain adj3 (isch?emia or pressure or perfusion or oedema or edema or injur* or trauma* or ICP or CPP)).ab,ti. (123234)

29 ((cerebral or intracranial) adj3 (isch?emia or pressure or perfusion or oedema or edema or injur ${ }^{\star}$ or trauma* or ICP or CPP or vasoconstrict*)).ab,ti. (98796)

30 or/12-29 (568932)

31 exp controlled study/ (7062015)

32 comparative study/ (854995)

33 randomi?ed.ab,ti. (837883)

34 placebo.ab. (289971)

$35{ }^{\star}$ Clinical Trial/ (19136)

36 major clinical study/ (3551322)

37 randomly.ab. (421716)

38 (trial or study).ti. (1953943)

39 or/31-38 (10935050)

40 (animals not (humans and animals)).sh. (374)

4139 not 40 (10935022)

4211 and 30 and 41 (3574)

43 remove duplicates from 42 (3519)

\section{Ebsco CINAHL Plus}

S1 (MH "Indomethacin") $(1,220)$

S2 (MH "Antiinflammatory Agents, Non-Steroidal") $(12,430)$

S3 (TI indomethacin $\left.{ }^{\star}\right)$ OR (AB indomethacin $\left.{ }^{\star}\right)(1,642)$

S4 (TI indometacin $\left.{ }^{\star}\right)$ OR (AB indometacin $\left.{ }^{\star}\right)(36)$

S5 (TI ketorolac) OR (AB ketorolac) (687)

S6 (TI IDM) OR (AB IDM) (144)

S7 (TI indocin) OR (AB indocin) (4)

$\mathrm{S} 8$ ( $\mathrm{TI}$ indocid) OR ( $\mathrm{BB}$ indocid) (2)

S9 (TI tivorbex) OR (AB tivorbex) (2)

S10 (TI nsaid\#) OR (AB nsaid\#) $(4,973)$

S11 (TI anti-inflammator $\left.{ }^{\star}\right)$ OR (AB anti-inflammator $\left.{ }^{\star}\right)(19,533)$

S12 S1 OR S2 OR S3 OR S4 OR S5 OR S6 OR S7 OR S8 OR S9 OR S10 OR S11 $(31,941)$

S13 (MH "Cerebral Ischemia+") $(16,005)$ 
S14 (MH "Intracranial Pressure") (2,248)

S15 (MH "Cerebrovascular Circulation") $(7,155)$

S16 (MH "Cerebral Edema+") $(1,739)$

S17 (MH "Intracranial Hypertension+") $(4,489)$

S18 (MH "Head Injuries") $(6,683)$

S19 (MH "Brain Injuries+") (25,977)

S20 (MH "Skull Fractures+") $(2,292)$

S21 (MH "Decompression, Surgical") (452)

S22 (MH "Decompressive Craniectomy") (169)

S23 (MH "Monitoring, Physiologic") $(18,857)$

S24 (MH "Intraoperative Monitoring") $(4,717)$

S25 (MH "Monitoring, Intracranial Pressure") (241)

S26 (TI (intracranial or cerebr* or brain) N3 hypertens ${ }^{\star}$ ) OR (AB (intracranial or cerebr ${ }^{\star}$ or brain) N3 hypertens $)(1,891)$

S27 (TI brain N3 (isch\#emia or pressure or perfusion or oedema or edema or injur* or trauma* or ICP or CPP)) OR (AB brain N3 (isch\#emia or pressure or perfusion or oedema or edema or injur ${ }^{\star}$ or trauma* or ICP or CPP)) $(25,287)$

S28 (TI (cerebral or intracranial) N3 (isch\#emia or pressure or perfusion or oedema or edema or injur or trauma* or ICP or CPP or vasoconstrict $\left.{ }^{\star}\right)$ ) OR (AB (cerebral or intracranial) N3 (isch\#emia or pressure or perfusion or oedema or edema or injur ${ }^{\star}$ or trauma* or ICP or CPP or vasoconstrict $\left.\left.{ }^{\star}\right)\right)(10,765)$

S29 S13 OR S14 OR S15 OR S16 OR S17 OR S18 OR S19 OR S20 OR S21 OR S22 OR S23 OR S24 OR S25 OR S26 OR S27 OR S28 (98,242)

S30 (TI randomi?ed) OR (AB randomi?ed) $(207,768)$

S31 (AB placebo) $(47,411)$

S32 (AB randomly) $(75,765)$

S33 (TI trial) $(94,043)$

S34 (MH "Clinical Trials+") $(265,240)$

S35 S30 OR S31 OR S32 OR S33 OR S34 $(412,061)$

S36 S12 AND S29 Limiters - Publication Type: Randomized Controlled Trial (16)

S37 S12 AND S29 AND S35 (101)

S38 S36 OR S37 (10)

\section{Clarivate Analytics Web of Science}

\#1 TOPIC: (indometacin or indomethacin or indometacina or indometacine or indometacinum or indocin or indocid or tivorbex or nsaid \$ or "anti-inflammator*") (183428)

\#2 TOPIC: (((intracranial or cerebr* or brain) near/3 hypertens $\left.{ }^{\star}\right)$ or (brain near/3 (isch\$emia or pressure or perfusion or oedema or edema or injur ${ }^{\star}$ or trauma* or ICP or CPP)) or ((cerebral or intracranial) near/3 (isch\$emia or pressure or perfusion or oedema or edema or injur ${ }^{\star}$ or trauma* or ICP or CPP or vasoconstrict*))) (188343)

\#3 TOPIC: (randomi?ed or placebo or randomly or trial) (1908463)

\#4 \#1 AND \#2 AND \#3 (598)

All searches run on Indexes=SCI-EXPANDED, CPCI-S Timespan=All years 


\section{VHL LILACS}

(tw:(indometacin\$ OR indomethacin\$ OR indocin OR indocid OR tivorbex OR ketorolac OR idm OR nsaid OR nsaids OR anti-inflammator\$)) AND (tw:((intracranial AND hypertens\$) OR (cerebr\$ AND hypertens\$) OR (brain AND hypertens\$) OR (brain AND ischaemia) OR (brain AND ischemia) OR (brain AND pressure) OR (brain AND perfusion) OR (brain AND oedema) OR (brain AND edema) OR (brain AND injur\$) OR (brain AND trauma\$) OR (brain AND ICP) OR (brain AND CPP) OR (cerebral AND ischaemia) OR (cerebral AND ischemia) OR (cerebral AND pressure) OR (cerebral AND perfusion) OR (cerebral AND oedema) OR (cerebral AND edema) OR (cerebral AND injur\$) OR (cerebral AND trauma\$) OR (cerebral AND ICP) OR (cerebral AND CPP) OR (cerebral AND vasoconstrict\$) OR (intracranial AND ischaemia) OR (intracranial AND ischemia) OR (intracranial AND pressure) OR (intracranial AND perfusion) OR (intracranial AND oedema) OR (intracranial AND edema) OR (intracranial AND injur\$) OR (intracranial AND trauma\$) OR (intracranial AND ICP) OR (intracranial AND CPP) OR (intracranial AND vasoconstrict\$))) AND (tw:(randomised OR randomized OR placebo OR randomly OR trial))

\section{OpenGrey}

(indomethacin* OR indometacin* OR indocin or indocid or tivorbex or ketorolac or IDM or nsaid or nsaids) AND ((intracranial AND hypertens) OR (cerebr* AND hypertens ${ }^{\star}$ ) OR (brain AND hypertens ${ }^{\star}$ ) OR (brain AND ischaemia) OR (brain AND ischemia) OR (brain AND pressure) OR (brain AND perfusion) OR (brain AND oedema) OR (brain AND edema) OR (brain AND injur ${ }^{\star}$ ) OR (brain AND trauma*) OR (brain AND ICP) OR (brain AND CPP) OR (cerebral AND ischaemia) OR (cerebral AND ischemia) OR (cerebral AND pressure) OR (cerebral AND perfusion) OR (cerebral AND oedema) OR (cerebral AND edema) OR (cerebral AND injur*) OR (cerebral AND trauma*) OR (cerebral AND ICP) OR (cerebral AND CPP) OR (cerebral AND vasoconstrict*) OR (intracranial AND ischaemia) OR (intracranial AND ischemia) OR (intracranial AND pressure) OR (intracranial AND perfusion) OR (intracranial AND oedema) OR (intracranial AND edema) OR (intracranial AND injur ${ }^{\star}$ ) OR (intracranial AND trauma*) OR (intracranial AND ICP) OR (intracranial AND CPP) OR (intracranial AND vasoconstrict*))

\section{World Health Organization International Clinical Trials Registry Platform}

Condition: intracranial or cerebr ${ }^{\star}$ or brain

Intervention: indomethacin* OR indometacin*

\section{Clinicaltrials.gov}

Condition: intracranial or cerebr* or brain

Intervention: indomethacin* OR indometacin*

\section{CONTRIBUTIONS OF AUTHORS}




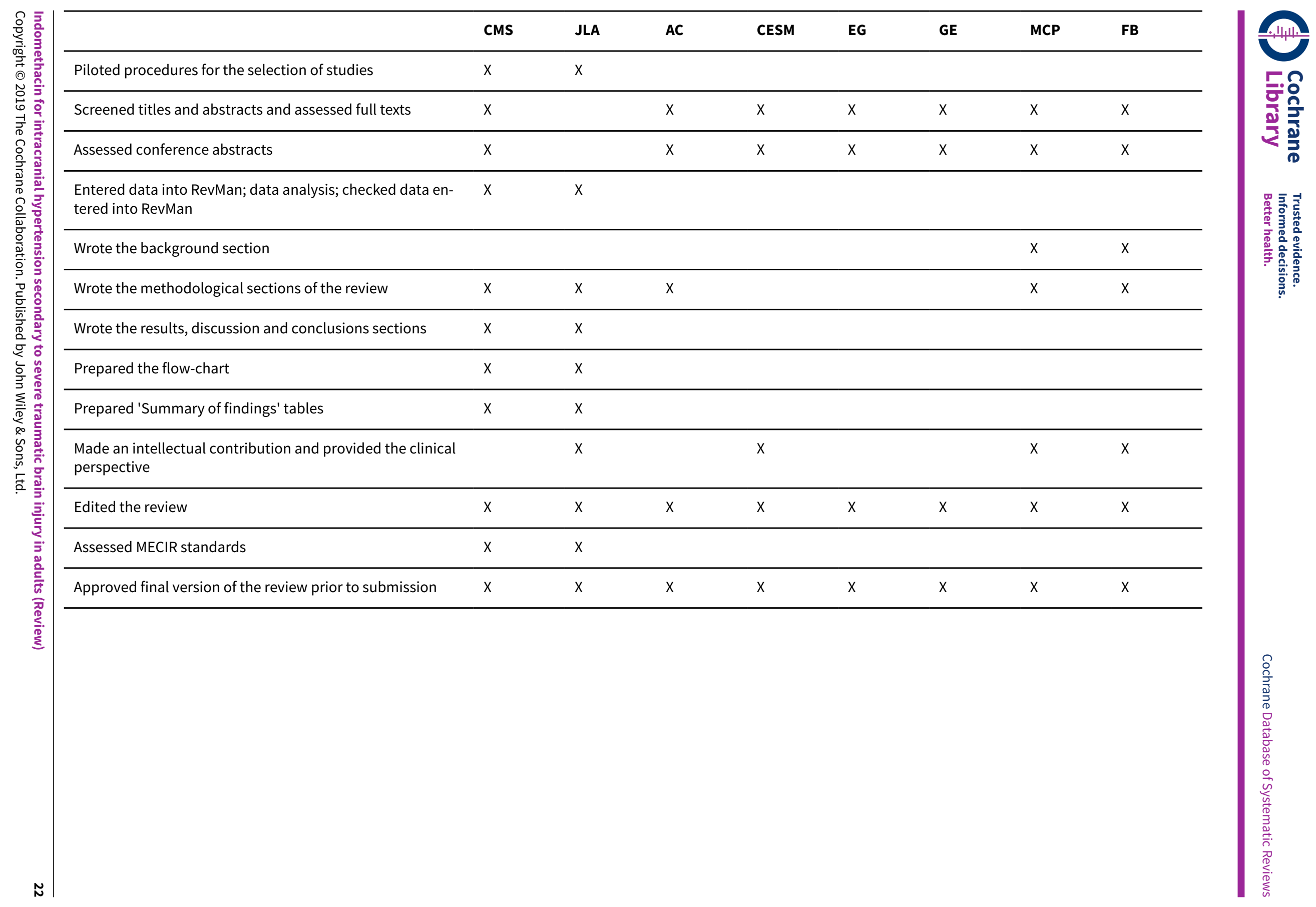


Carlos Martin Saorido (CMS), Jesús López-Alcalde (JLA), Carlos Enrique Sánchez Martín (CESM), Elena Garcia Garcia (EG), Gema Escobar Aguilar (GE), Carolina Palermo (CP), Agustín Ciapponi (AC), Fernando G Baccaro (FB).

CMS is the guarantor of this review.

\section{DECLARATIONSOF INTEREST}

Carlos Martín-Saborido: none known

Jesús López-Alcalde: none known

Agustín Ciapponi: none known

Carlos Enrique Sánchez Martín: none known

Elena Garcia Garcia: none known

Gema Escobar Aguilar: none known

Maria Carolina Palermo: none known

Fernando G Baccaro: none known

\section{SOURCES OF SUPPORT}

\section{Internal sources}

- No sources of support supplied

\section{External sources}

- Institute for Clinical Effectiveness and Health Policy, Argentina.

Logistical support

- National Institute for Health Research (NIHR), Department of Health, UK.

The views and opinions expressed therein are those of the authors and do not necessarily reflect those of the NIHR, NHS or the Department of Health.

\section{DIFFERENCES BETWEEN PROTOCOLANDREVIEW}

\section{Search methods}

We handsearched the conference proceedings for the Argentine Society of Intensive Therapy (SATI) from 2001 rather than from 1990, as the proceedings from 1990 to 2001 were not available. With regard to the proceedings of the Intensive Care Society and Riverside Group, we identified some volumes through the website (1997, 1998, 2001, 2002 and 2003). We wrote to the Riverside Group twice requesting the remaining volumes, but we had not received an answer at the time of finishing this review. 